\title{
Response of the ionospheric electron density to different types of seismic events
}

\author{
Y. He ${ }^{1}$, D. Yang ${ }^{1}$, J. Qian ${ }^{2}$, and M. Parrot ${ }^{3}$ \\ ${ }^{1}$ Institute of Geophysics, China Earthquake Administration, Beijing, China \\ ${ }^{2}$ Institute of Earthquake Science, China Earthquake Administration, Beijing, China \\ ${ }^{3}$ Laboratoire de Physique et Chimie de l'Environnement et de l'Espace, Centre National de la Recherche Scientifique, \\ Orléans, France
}

Received: 15 April 2011 - Revised: 28 June 2011 - Accepted: 29 June 2011 - Published: 5 August 2011

\begin{abstract}
The electron density data recorded by the Langmuir Probe Instrument (ISL, Instrument Sonde de Langmuir) onboard the DEMETER satellite have been collected for nearly $4 \mathrm{yr}$ (during 2006-2009) to perform a statistical analysis. During this time, more than 7000 earthquakes with a magnitude larger than or equal to 5.0 occurred all over the world. For the statistical studies, all these events have been divided into various categories on the basis of the seismic information, including Southern or Northern Hemisphere earthquakes, inland or sea earthquakes, earthquakes at different magnitude levels, earthquakes at different depth levels, isolated events and all events. To distinguish the preearthquake anomalies from the possible ionospheric anomalies related to the geomagnetic activity, the data were filtered with the $K_{p}$ index. The statistical results obviously show that the electron density increases close to the epicentres both in the Northern and the Southern Hemisphere, but the position of the anomaly is slightly shifted to the north in the Northern Hemisphere and to the south in the Southern Hemisphere. The electron density related to both inland and sea earthquakes presents an anomaly approximately close to the epicentres, but the anomaly for sea earthquakes is more significant than for inland earthquakes. The intensity of the anomalies is enhanced when the magnitude increases and is reduced when the depth increases. A similar anomaly can also be seen in the statistical results concerning the isolated earthquakes. All these statistical results can help to better understand the preparation process of the earthquakes and their influence up to the ionospheric levels.
\end{abstract}

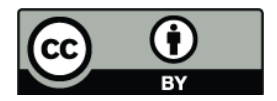

Correspondence to: D. Yang (ydmgeomag@263.net)

\section{Introduction}

In the last decades, widespread researches on earthquake prediction have shown that earthquake precursors exist not only in the lithosphere, but also in the atmosphere and the ionosphere (Hayakawa, 1999; Hayakawa and Fujinawa, 1994; Hayakawa and Molchanov, 2002; Hayakawa et al., 2004; Parrot and Johnston, 1993; Pulinets, 2007, 2009). Therefore, the use of ionospheric data to investigate earthquake precursors has become a new approach to consider this complex problem. In recent years, many papers and special monographs have been published on seismo-ionospheric phenomena and most of these were directly or indirectly related to the variation of the ionospheric electron density $\left(N_{\mathrm{e}}\right)$. Some authors reported that disturbances can be found in the vicinity of earthquakes, using the TEC (Total Electron Content) data calculated from the GPS (Global Position System) observations (e.g., Calais and Minister, 1995; Zaslavski et al., 1998; Liu et al., 2004; Lognonné et al., 2006). Other authors analysed the data recorded by ground-based vertical sounding stations and claimed that the variation of foF 2 or the spreadEs effects have some relation with earthquakes (e.g., Liperovskaya et al., 2008; Liperovsky et al., 2005, 2008). While others stated that the anomalies can be detected by studying the data recorded by instruments onboard satellites (Parrot and Mogilevsky, 1989; Parrot et al., 2006; Hayakawa et al., 2000; Molchanov et al., 2006; Sarkar et al., 2007; Zhu et al., 2008; Rozhnoi et al., 2008; Ouyang et al., 2008; He et al., 2009; Zhang et al., 2009; Akhoondzadeh et al., 2010). But, as many geophysical phenomena, earthquakes are sophisticated and many factors, including magnitude, depth, location, mechanism and so on, are needed to describe one event. This gives a high uncertainty to the earthquake precursors.

Published by Copernicus Publications on behalf of the European Geosciences Union. 
Furthermore, the dataset used in each study may derive from different experiments. It makes that the precursor parameters are dissimilar from one case to another. So it is necessary to find an effective method and enough data to extract characteristics which may connect with each earthquake. In this regard, scientists have also done some statistical works on the seismo-ionospheric precursors. Afonin et al. (1999) used the Intercosmos- 24 satellite data $(\sim 7000 \mathrm{~h})$ to analyse the correlation coefficients between the variation of the ion density and the earthquake events, and they discovered a reliable correlation between the global distribution of seismic activity and ion density variations (at $500-700 \mathrm{~km}$ altitude), especially in the longitude range from $110^{\circ}$ to $190^{\circ}$. The correlation coefficients is better than 0.6-0.8. Nemec et al. (2008) studied more than $2 \mathrm{yr}$ of electric field data and observed a statistically significant decrease by $4-6 \mathrm{~dB}$ of the measured wave intensity shortly before $(0-4 \mathrm{~h})$ surface earthquakes. Shimpei Kon et al. (2010) performed a statistical test using TEC at the time of $M_{\mathrm{S}}>=6.0$ earthquakes during the 12-yr period of May 1998-May 2010 around Japan. They found significant positive TEC anomalies 1-5 days before earthquakes within $1000 \mathrm{~km}$ from the epicentres.

Since the DEMETER satellite was continuously in operation for many years, it accumulates ample observation data and a statistical study has been conducted with these data in relation with global scale earthquakes with $M_{\mathrm{S}}>=5.0$. The aim of this paper is to explore the possible electron density anomalies prior to earthquakes. The DEMETER experiment which gives the electron density $N_{\mathrm{e}}$ is briefly described in Sect. 2. The method of analysis is shown in Sect. 3. Results are presented in Sect. 4 as a function of the different types of seismic events, whereas conclusions are provided in Sect. 5.

\section{The dataset}

This study is based on the French DEMETER satellite. It is the first satellite which is especially dedicated to earthquake studies and volcano monitoring. Its scientific goal is to detect abnormality that might exist in the ionosphere before an earthquake occurrence or volcano eruptions. This satellite was launched on 29 June 2004. It has an almost circular sun-synchronous orbit (10:30 LT in day sector, 22:30 LT in night sector). The orbital altitude is about $710 \mathrm{~km}$ (adjusted to $660 \mathrm{~km}$ at the end of 2005) and the orbital inclination is $98^{\circ}$. The scientific instruments perform measurements between $-65^{\circ}$ and $+65^{\circ}$ in geomagnetic latitude (Cussac et al., 2006). The $N_{\mathrm{e}}$ data used in this paper are recorded by the ISL (Instrument Sonde de Langmuir) experiment onboard the satellite. The time resolution is $1 \mathrm{~s}$. Details about ISL can be found in Lebreton et al. (2005). As the height of the orbit was adjusted to $660 \mathrm{~km}$ from $710 \mathrm{~km}$ and the variation characteristic of $N_{\mathrm{e}}$ changes with the altitude (He et al., 2010), only the data from 2006 to the beginning of 2009 (more than $3 \mathrm{yr}$ and about 30000 half-orbits) were used

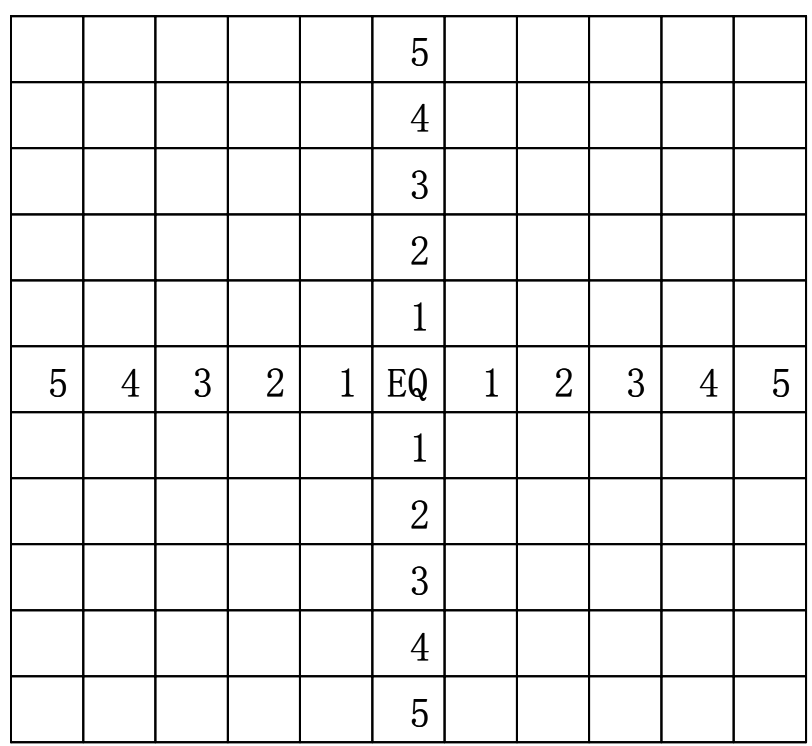

Fig. 1. Research area centre around one earthquake.

here. Considering that the ionospheric ionization is significantly larger during the day, any potential changes caused by seismic activity may, therefore, be overwhelmed by this stronger influence (Nemec et al., 2008). Then this study only considers the nighttime data. According to the USGS catalog (http://neic.usgs.gov/neis/epic/epic_global.html), about 7000 earthquakes with a magnitude larger than or equal to 5.0 occurred all over the world during the analysed period. Different parameters are considered in this paper: occurrence in the Northern or the Southern Hemisphere, occurrence on land or below the sea, magnitude and depth, isolated events or not. To distinguish the pre-earthquake anomalies from the other anomalies related to the geomagnetic activity, the $K_{p}$ indexes given by the World Data Center in Kyoto (http://wdc.kugi.kyoto-u.ac.jp/index.html) were also taken into account.

\section{Method of analysis}

After the collection of data from the micro-satellite DEMETER, a robust three-step data processing has been used. The first step is to dispatch the data on a grid map. In this step, the Earth surface is divided into cells with 2 degree resolution both in latitude and longitude. Then, for a given time interval $(\sim 30$ s) all the available data samples $(\sim 30)$ were attributed to the corresponding cell. At the end of this step, the data base contains every $30 \mathrm{~s}$, the date and the time, the $N_{\mathrm{e}}$ values in the corresponding cell, the cell latitude and longitude, the $K_{p}$ value at this time, and the column and the row indexes of the grid. This is convenient in performing a statistical analysis at a given place and under given conditions. 
The second step of data processing is to extract anomalies at the time of each earthquake. As it is known, the important work to extract anomalies is to determine the normal background. Previous research has shown that the variations in the ionosphere are extraordinarily complicated and highly dynamic (Sharma et al., 2008). It depends on solar and geomagnetic activities, season, latitude, longitude, altitude and other unknown parameters (Rishbeth, 1998; Zou et al., 2000; Chen et al., 2009). In addition, earthquakes occur at different times and different locations. Therefore, a background was constructed for each earthquake event with a shorter time span, a strict consideration of the geomagnetic conditions, and a smaller research region. This may be a better way to distinguish pre-earthquake anomalies from the anomalies related to other parameters.

As shown in Fig. 1, a square area centred around one earthquake and containing 121 cells in all, is considered as the research zone. In order to explore the pre-earthquake phenomena, only the data before the earthquake occurrence were used. In each cell, the data with $K_{p}<2+$ and the time interval 31 to 75 days before the earthquake were used to construct the background, and the data with $K_{p}<3+$ and the time interval 1 to 30 days before the earthquake were analysed for comparison. This time span ensures that each cell has enough data, and that it, as much as possible, avoid the influence of yearly and seasonal variations.

The mean values of the data during background and seismo-active times are calculated and noted by $\overline{b_{i j}}$ and $\overline{g_{i j}}$, respectively. Their formulas are given by Eqs. (1) and (2).

$$
\begin{gathered}
\overline{b_{i j}}=\frac{\sum_{t=-75}^{-31} \sum_{k=0}^{N_{t}} x_{i j t k}}{\sum_{t=-75}^{-31} N_{t}} \\
\overline{g_{i j}}=\frac{\sum_{t=-30}^{-1} \sum_{k=0}^{N_{t}} x_{i j t k}}{\sum_{t=-30}^{-1} N_{t}}
\end{gathered}
$$

where the parameters $x$ are the $N_{\mathrm{e}}$ values, $N$ is the number of values in one day, $i$ and $j$ are the column number and the row number of the grid, respectively, $t$ is related to days before the earthquake (the negative numbers mean before earthquake) and $k$ is the number of data in the cell $(i, j)$. According to Fig. $1, i$ and $j$ vary from -5 to +5 .

At the same time, the standard deviation of the background data $\sigma_{b i j}$ collected in each cell was also calculated by the following equation

$$
\sigma_{b i j}=\sqrt{\frac{\sum_{t=-75}^{-30} \sum_{k=0}^{N_{t}}\left(x_{i j t k}-\overline{b_{i j}}\right)^{2}}{\sum_{t=-75}^{-31} N_{t}} .}
$$

Then the variation of the data before each earthquake, relative to the background data in each cell, can be denoted by Eq. (4).

$R_{i j}=\frac{\left(\overline{g_{i j}}-\overline{b_{i j}}\right)}{\sigma_{b i j}}$

The third step of data processing concerns the final statistics with all seismic events. The anomaly extracted from each earthquake in the second step is individual and special. It cannot represent the common features of the precursors. Therefore, all results calculated during the second step are now collected, and the mean of all cells at the same position is computed. A random anomaly may be reduced and an earthquake anomaly may be strengthened by this way. The formula is displayed in the following equation

$\bar{\Re}_{i j}=\frac{\sum_{m=0}^{M} R_{i j m}}{M}$

where $M$ is the number of earthquakes and $\bar{\Re}_{i j}$ is the mean of all the results computed by the second step data processing. At least, a relative variation can be obtained from this final statistical result.

\section{Results}

The data processing method introduced above is applied to different categories of seismic events. Considering the important variation of the density at higher latitudes near the geomagnetic poles, only the middle and low latitude (latitude between $-50^{\circ}$ and $+50^{\circ}$ ) satellite data are used in this statistical research.

First, Fig. 2 shows the statistical analysis result of the seismic events on a global scale with the magnitude greater than or equal to 5.0. A maximum is observed close to the epicentres.

Second, considering that the ionospheric disturbances induced by the earthquakes may present some differences in the Northern and Southern Hemispheres (Pulinets and Boyarchuk, 2004), the earthquake database has been separated according to the position of the epicentres. All earthquakes with the magnitude greater than or equal to 5.0 were also used in this statistic. The results are displayed in Fig. 3. It can be observed that the maximum of the disturbances is slightly shifted to the north for the earthquakes occurring in the Northern Hemisphere, and to the south for the earthquakes occurring in the Southern Hemisphere.

Third, the statistic results concerning the inland and the sea seismic events are displayed in Fig. 4. The left panel is devoted to the inland earthquakes and the right panel to the earthquakes occurring below the sea. All earthquakes with a magnitude greater than or equal to 5.0 are used in these statistics. One can see that the anomaly is more obvious for 

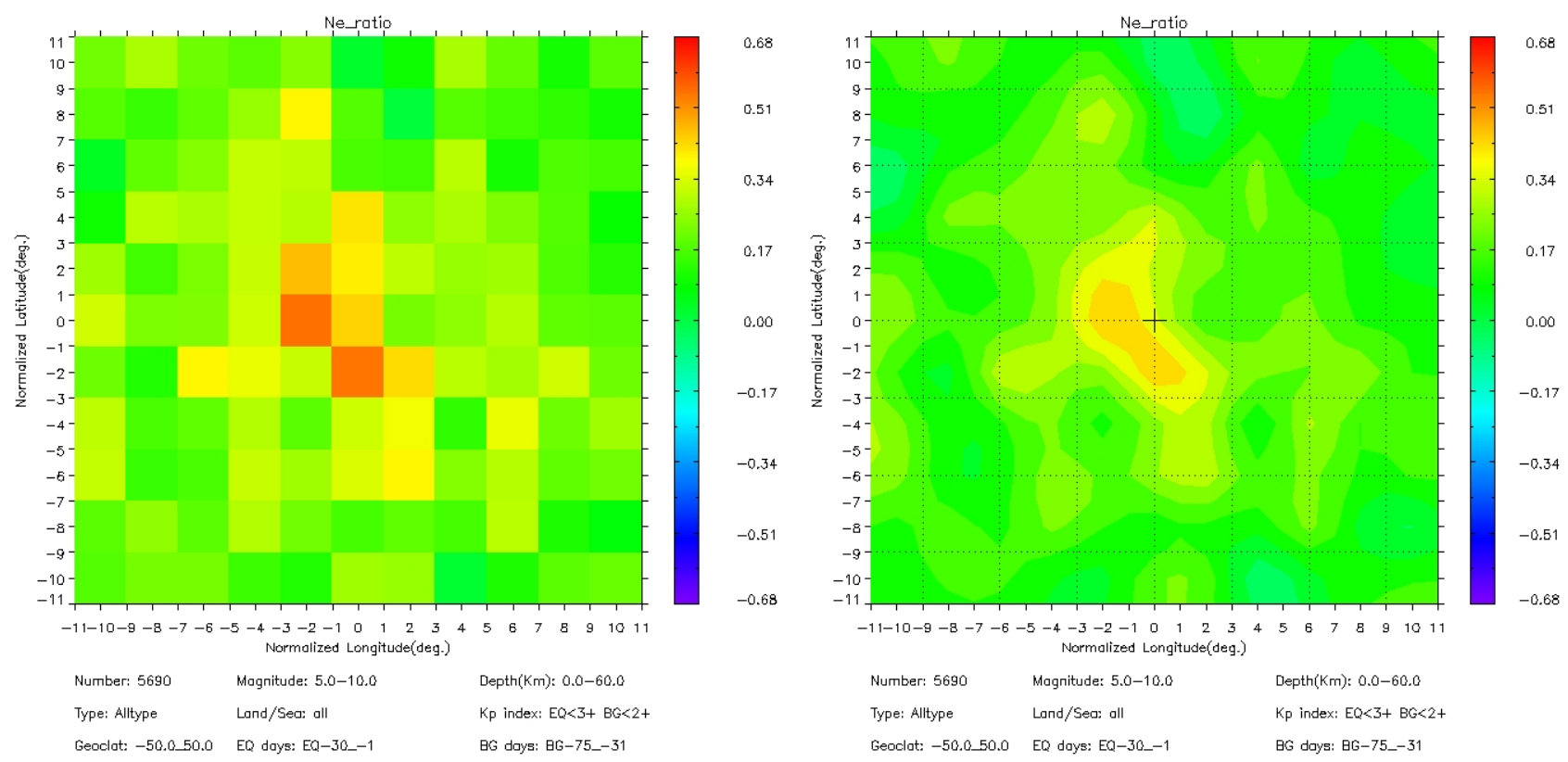

Fig. 2. (Left panel) Statistical results concerning the seismic events on a global scale. (Right panel) Same information as in the left panel but the results have been smoothed. The position 0 in latitude and in longitude corresponds to the location of the epicentres. The values of the parameters given by Eq. (5) are colour coded according to the scale on the right of the panels. The information below the panels is related to the values of the parameters in the earthquake database which have been selected for the current statistic.
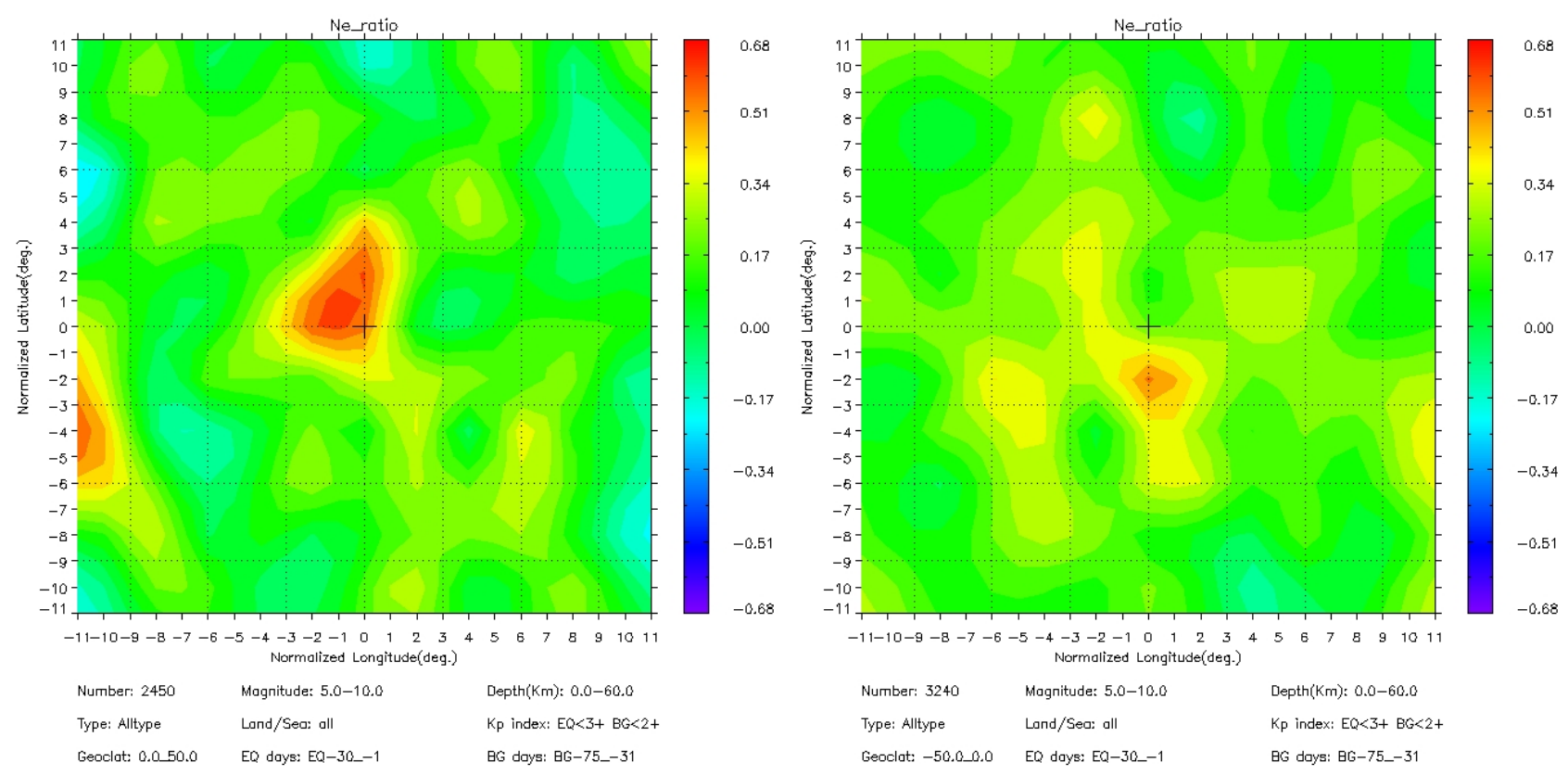

Fig. 3. The plots are similar to the right panel of Fig. 2, but it concerns statistical results with seismic events occurring in the Northern Hemisphere (left panel) and in the Southern Hemisphere (right panel).

sea earthquakes than for inland earthquakes. The different conductivity and permeability between sea and land may be the main reasons.

Fourth, the statistical results of the earthquakes with different magnitude levels, including $M_{\mathrm{S}}>=5.0, M_{\mathrm{S}}>=5.5$, and $M_{\mathrm{S}}>=6.0$, are shown in Fig. 5. It can be observed that the intensity of the anomalies around the epicentres increased with the magnitude. As it is normally expected, the perturbation is the more important as the magnitude of the earthquakes is large. 

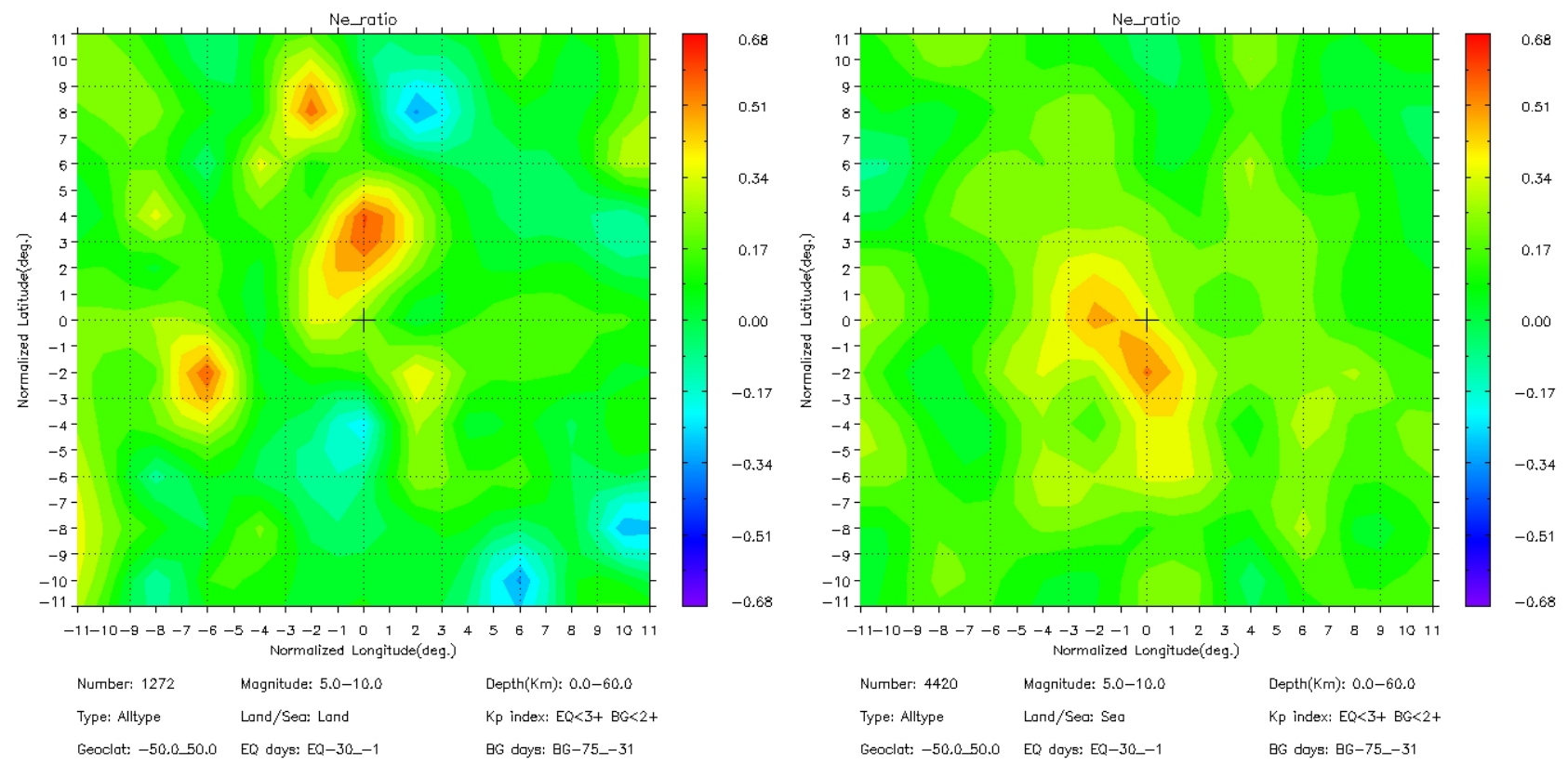

Fig. 4. The plots are similar to the right panel of Fig. 2, but it concerns statistical results of seismic events located in mainland (left panel) and below the sea (right panel).
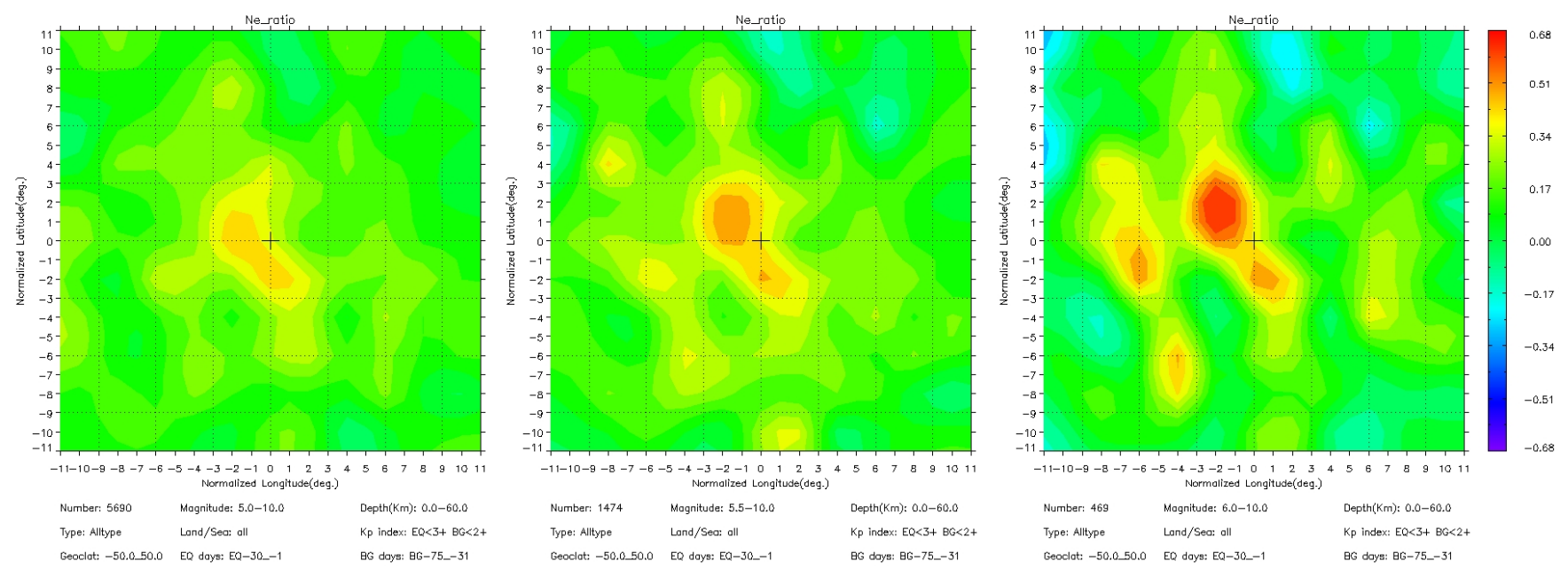

Fig. 5. The plots are similar to the right panel of Fig. 2, but it concerns statistical results of seismic events at different magnitude levels (left panel $M_{\mathrm{S}}>=5.0$, middle panel $M_{\mathrm{S}}>=5.5$, and right panel $M_{\mathrm{S}}>=6.0$ ). The left panel is similar to the one in Fig. 2 and is just here to facilitate the comparison.

Fifth, Fig. 6 illustrated the statistical results of the earthquakes with different depth levels $(0 \sim 30 \mathrm{~km}, 0 \sim 60 \mathrm{~km}$ and $60 \sim 500 \mathrm{~km})$. The statistic here uses earthquakes with a magnitude greater than or equal to 5.0. As shown in the figure, the intensity of the anomaly around the epicentre decreases when the depth increases. That is to say, anomalies are more easily observed during shallow earthquakes than during deep earthquakes.
Sixth, in order to not mix pre- and post-seismic effects, the aftershock data which are too close to the time of the main shock are not taken into account. It is known that, at the time of the shock, the earthquakes induce an Acoustic Gravity Wave (AGW) which can propagate upwards and perturbs the ionosphere. The duration of the effect of this AGW is only a few hours. Therefore, the data recorded above a seismic area, which followed an earthquake occurrence by 1 day, were left out in this sixth part of the statistic. The corresponding result 

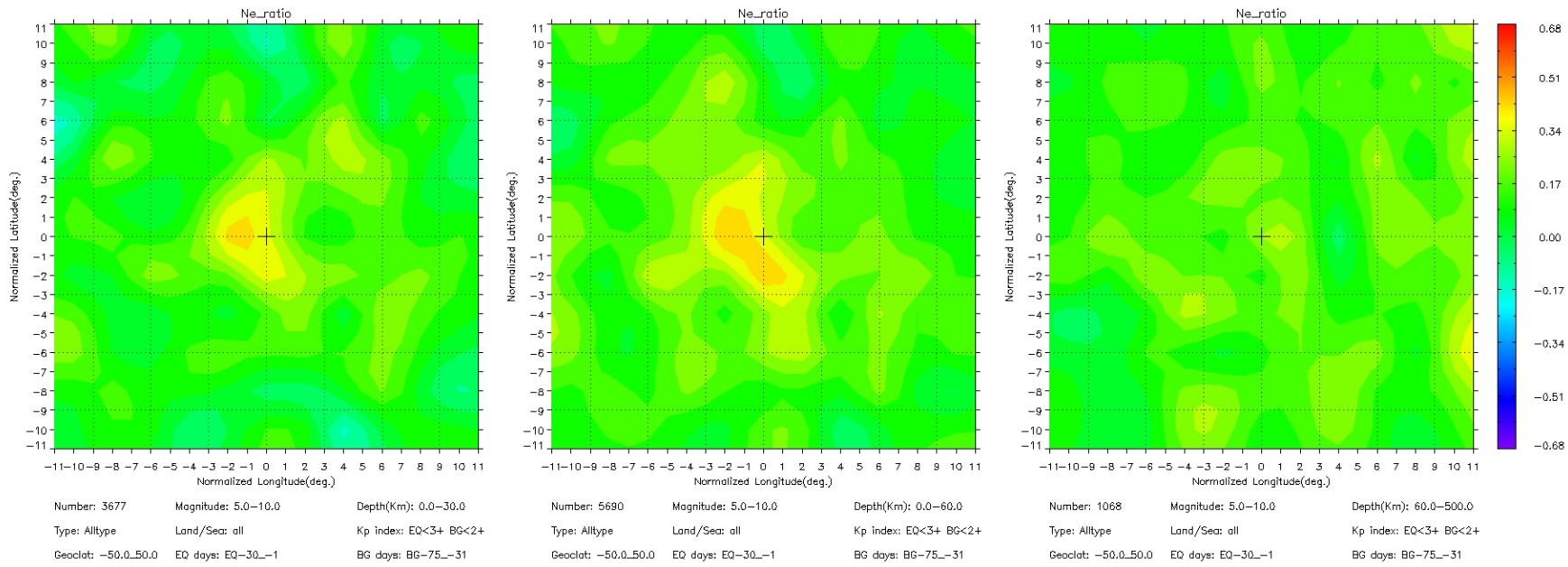

Fig. 6. The plots are similar to the right panel of Fig. 2, but it concerns statistical results with seismic events at different depth levels (the depth was $0 \sim 30 \mathrm{~km}$ in the left panel, $0 \sim 60 \mathrm{~km}$ in the middle panel and $60 \sim 500 \mathrm{~km}$ in the right panel). The middle panel is similar to the one in Fig. 2 and is just here to facilitate the comparison.
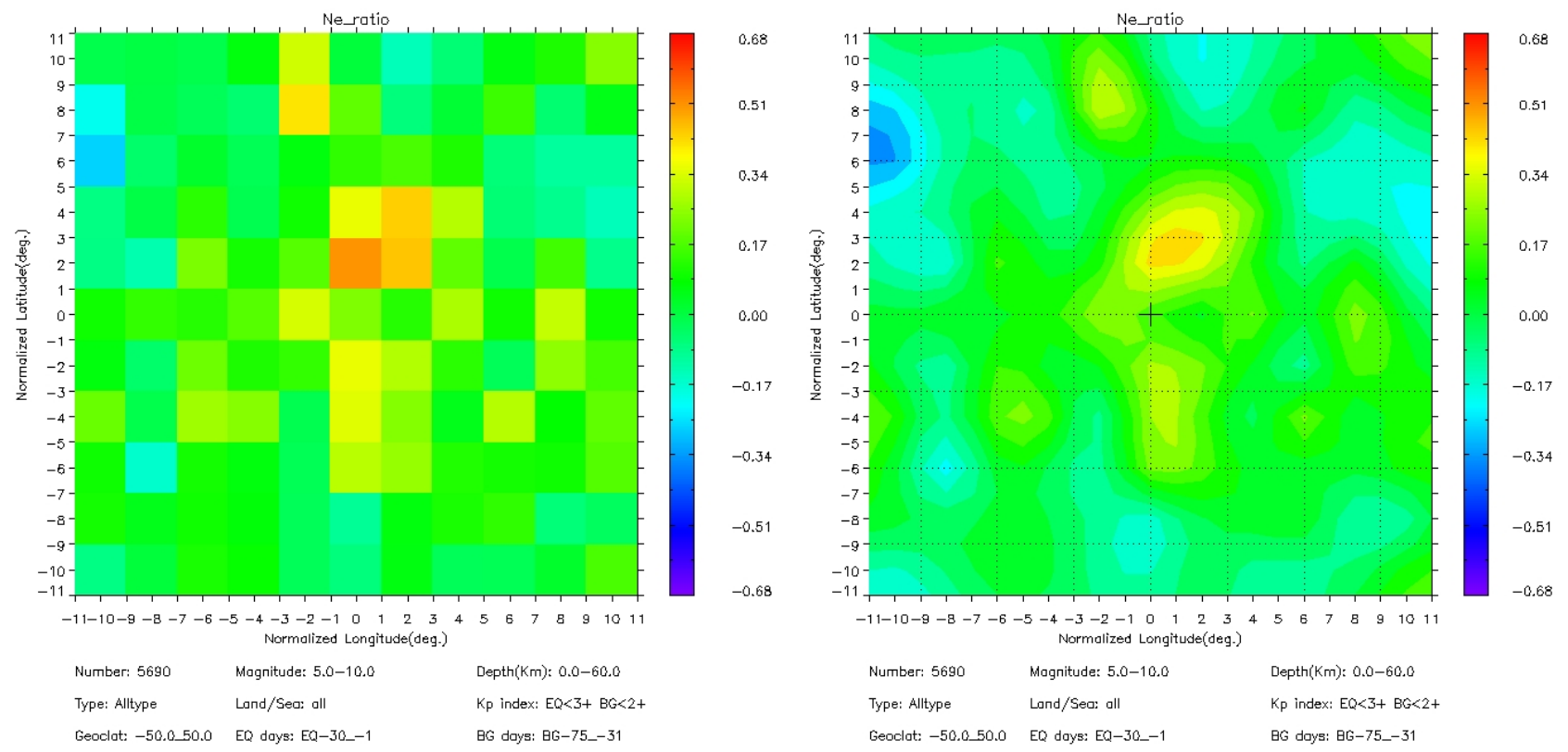

Fig. 7. The plots are similar to those of Fig. 2, but it concerns statistical results when the post seismic effect is suppressed.

is presented in Fig. 7. An anomaly similar to the one observed before can be found around the epicentres too. This demonstrates that the anomaly looks like a real pre-seismic effect.

\section{Discussions}

In this paper, the electron density data recorded close to the time of earthquakes (up to 30 days before) have been compared with the same data recorded well before (from 31 up to 75 days before). The statistical study on all events shows that there are anomalies near the epicentres prior to the occurrence of earthquakes. This conclusion is consistent with many previous studies using other datasets. It is found that the spatial scale of the anomaly is approximately $350 \mathrm{~km}$. This agrees well with the size of the earthquake preparation zone estimated by Dobrovolsky et al. (1979). It also corresponds relatively to the statistical results of Nemec et al. $(2008,2009)$ which are related to a different ionospheric parameter (ELF/VLF wave). 
The other statistical results show that obviously increased anomalies close to epicentres can be found both in the Northern and Southern Hemispheres, but the position of the anomaly is slightly shifted to the north in the Northern Hemisphere and to the south in the Southern Hemisphere. Previous studies show that the maximum affected area in the ionosphere does not coincide with the vertical projection of the epicentre of the impending earthquake (Pulinets et al., 2003) and is shifted towards the equator in high and middle latitudes (Pulinets, 2004).

Both land and marine earthquakes had anomaly approximate to epicentre, and the anomaly of sea earthquakes was more significantly than inland earthquakes. The intensity of the anomalies increased with the magnitude rising and decreased with the depth increasing. A similar anomaly can also be seen in the statistical result with the isolate earthquakes. All the results confirm that the anomaly near the epicentres has some relation with the earthquake preparation. As a number of corresponding coupling mechanisms have been proposed, including geochemical process, acoustic propagation, electromagnetic radiation and so on (Hayakawa et al., 2004), these results may help us to better understand these coupling mechanisms and the earthquake preparation process.

In spite of these statistical results showing that the anomaly is obvious and its position is remarkable, one should keep in mind that every earthquake does not present an anomaly prior to events at right position, and it is difficult for us to predict an earthquake depending on any changes in independent parameters. In other words, it is not possible to fully handle this point because the survey of a given seismic area is not complete twenty-four hours a day with a single satellite. However, there is some distance away from earthquake prediction. In the future, further researches based on more data and more parameters will be done to try to understand the nature of these short-term seismic precursors statistically revealed.

Acknowledgements. This study is supported by the National Key Technology Research and Development Programme (No. 2008BAC35B02). The authors are grateful to the Guest Investigator programme issued by CNES for the DEMETER mission for supplying the raw data. It is based on observations with the Langmuir probe experiment ISL embarked on DEMETER. The authors thank J. P. Lebreton the PI of the Langmuir probe experiment for the use of the data.

Edited by: M. E. Contadakis

Reviewed by: two anonymous referees

\section{References}

Afonin, V. V., Molchanov, O. A., Kodama, T., Hayakawa, M., and Akentieva, O. A.: Statistical study of ionospheric plasma response to seismic activity: Search for reliable result from satellite observations, in: Atmospheric and Ionospheric Electromagnetic
Phenomena Associated with Earthquakes, Terra Sci. Pub. Co., Tokyo, 597-618, 1999.

Akhoondzadeh, M., Parrot, M., and Saradjian, M. R.: Electron and ion density variations before strong earthquakes $(M>6.0)$ using DEMETER and GPS data, Nat. Hazards Earth Syst. Sci., 10, 718, doi:10.5194/nhess-10-7-2010, 2010.

Calais, E. and Minster, J. B.: GPS detection of ionospheric perturbations following the January 17, 1994, Northridge earthquake[J], Geophys. Res. Lett., 22, 1045-1048, 1995.

Chen, Y., Liu, L., Wan, W., Yue, X., and Su, S. Y.: Solar activeity dependence of the topside ionosphere at low latitudes, J. Geophys. Res., 114, A08306, doi:10.1029/2008JA013957, 2009.

Cussac, T., Clair, M. A., Ultre-Guerard, P., Buisson, F., LassalleBalier, G., Ledu, M., Elisabelar, C., Passot, X., and Rey, N.: The DEMETER microsatellite and ground segment, Planet. Space Sci., 54(5), 413-427, 2006.

Dobrovolsky, I. P., Zubkov, S. I., and Miachkin, V. I.: Estimation of the size of earthquake preparation zones, Pure Appl. Geophys., 117(5), 1025-1044, doi:10.1007/BF00876083, 1979.

Hayakawa, M.: Atmospheric and Ionospheric Electromagnetic Phenomena Associated with Earthquakes, Terrapub, Tokyo, 996997, 1999.

Hayakawa, M.: Electromagnetic phenomena associated with earthquakes: A frontier in terrestrial electromagnetic noise environment, Recent Res. Dev. Geophys., 6, 81-112, 2004.

Hayakawa, M. and Fujinawa, Y.: Electromagnetic Phenomena related to earthquake prediction, Terra Scientific Publishing Company (TERRAPUB), Tokyo, 1994.

Hayakawa, M. and Molchanov, O. A.: Seismo-Electromagnetics: Litho-sphere-Atmosphere-Ionosphere Coupling, Terrapub, Tokyo, 477-487, 2002.

Hayakawa, M., Molchanov, O. A., Kodama, T., Afonin, V. V., and Akentieva, O. A.: Plasma density variations observed on a satellite possibly related to seismicity, Adv. Space Res., 26, 12771280, 2000.

Hayakawa, M., Molchanov, O. A., Biagi, P., and Vallianatos, F.: Special issue: Seismo electromagnetics and related phenomena, Phys. Chem. Earth, 29, 459-462, 2004.

He, Y. F., Yang, D. M., Chen, H. R., Qian, J. D., Zhu, R., and Parrot, M.: SNR changes of VLF radio signals detected onboard the DEMETER satellite and their possible relationship to the Wenchuan earthquake, Sci. China Ser. D-Earth Sci., 52(6), 754763, doi:10.1007/s11430-009-0064-5, 2009.

He, Y. F., Yang, D. M., Zhu, R., Qian, J. D., and Parrot, M.: Variations of electron density and temperature in ionosphere based on the DEMETER ISL data, Earthq. Sci., 23, 349-355, doi:10.1007/s11589-010-0732-8, 2010.

Kon, S., Nishihashi, M., and Hattori, K.: Ionospheric anomalies possibly associated with M P6.0 earthquakes in the Japan area during 1998-2010: Case studies and statistical study, J. Asian Earth Sci., doi:10.1016/j.jseaes.2010.10.005, 2010.

Liperovskaya, E. V., Biagi, P.-F., Meister, C.-V., and Rodkin, M. V.: foF2 seismo-ionospheric effect analysis: actual data and numerical simulations, Nat. Hazards Earth Syst. Sci., 8, 1387-1393, doi:10.5194/nhess-8-1387-2008, 2008.

Liperovsky, V. A., Meister, C.-V., Liperovskaya, E. V., Vasil'eva, N. E., and Alimov, O.: On spread- $E_{S}$ effects in the ionosphere before earthquakes, Nat. Hazards Earth Syst. Sci., 5, 59-62, doi:10.5194/nhess-5-59-2005, 2005. 
Liperovsky, V. A., Pokhotelov, O. A., Meister, C.-V., and Liperovskaya, E. V.: Physical models of coupling in the lithosphereatmosphere-ionosphere system before earthquakes, Geomagn. Aeronomy+, 48(6), 795-806, doi:10.1134/S0016793208060133, 2008.

Lebreton, J. P., Stverak, S., Travnicek, P., Maksimovic, M., Klinge, D., Merikallio, S., Lagoutte, D., Poirier, B., Blelly, P. L., Kozacek, Z., and Salaquarda, M.: The ISL Langmuir probe experiment processing onboard DEMETER: Scientific objectives, description and first results, Planet. Space Sci., 54(5), 472-486, 2005.

Liu, J. Y., Chuo, Y. J., Shan, S. J., Tsai, Y. B., Chen, Y. I., Pulinets, S. A., and Yu, S. B.: Pre-earthquake ionospheric anomalies registered by continuous GPS TEC measurements, Ann. Geophys., 22, 1585-1593, doi:10.5194/angeo-22-1585-2004, 2004.

Lognonné, P., Artru, J., Garcia, R., Crespon, F., Ducic, V., Jeansou, E., Occhipinti, G., Helbert, J., Mmeaux, G., and Godet, P. E.: Groundbased GPS imaging of ionospheric post-seismic signal[J], Planet. Space Sci., 54, 528-540, 2006.

Molchanov, O., Rozhnoi, A., Solovieva, M., Akentieva, O., Berthelier, J. J., Parrot, M., Lefeuvre, F., Biagi, P. F., Castellana, L., and Hayakawa, M.: Global diagnostics of the ionospheric perturbations related to the seismic activity using the VLF radio signals collected on the DEMETER satellite, Nat. Hazards Earth Syst. Sci., 6, 745-753, doi:10.5194/nhess-6-745-2006, 2006.

Nemec, F., Santolík, O., Parrot, M., and Berthelier, J. J.: Spacecraft observations of electromagnetic perturbations connected with seismic activity, Geophys. Res. Lett., 35, L05109, doi:10.1029/2007GL032517, 2008.

Nemec, F., Santolík, O., and Parrot, M.: Decrease of intensity of ELF/VLF waves observed in the upper ionosphere close to earthquakes: A statistical study, J. Geophys. Res., 114, A04303, doi:10.1029/2008JA013972, 2009.

Ouyang, X. Y., Zhang, X. M., Shen, X. H., Liu, J., Qian, J. D., Cai, J. A., and Zhao, S. F.: Ionospheric $N_{\mathrm{e}}$ disturbances before 2007 Puer, Yunnan, China, earthquake, ACTA SEISMOLOGICA SINICA, 21(4), 425-437, doi:10.1007/s11589-008-0425-8, 2008.

Parrot, M. and Johnston, M.: Special Issue: Seismoelectromagnetic Effects, Phys. Earth Planet. Int., 77, 137 pp., 1993.

Parrot, M. and Mogilevsky, M. M.: VLF emissions associated with earthquakes and observed in the ionosphere and the magnetosphere, Phys. Earth Planet. Int., 57, 86-99, 1989.

Parrot, M., Berthelier, J. J., Lebreton, J. P., Sauvaud, J. A., Santolík, O., and Blecki J.: Examples of unusual ionospheric observations made by the DEMETER satellite over seismic regions, Phys. Chem. Earth, 31, 486-495, doi:10.1016/j.pce.2006.02.011, 2006.
Pulinets, S. A.: Ionospheric precursors of earthquakes, Recent advances in theory and practical applications, Tao, 15(3), 413-435, 2004.

Pulinets, S. A.: Natural Radioactivity, Earthquakes, and the Ionosphere, Eos Trans. AGU, 88(20), 217-218, doi:10.1029/2007EO200001, 2007.

Pulinets, S. A.: Physical mechanism of the vertical electric field generation over active tectonic faults, Adv. Space Res., 44(6), 767-773, doi:10.1016/j.asr.2009.04.038, 2009.

Pulinets, S. A. and Boyarchuk, K. A.: Ionospheric Precursors of Earthquakes, Springer Verlag Publ, Berlin, 288 pp., 2004.

Pulinets, S. A., Legen, A. D., Gaivoronskaya, T. V., and Depuev, V. K.: Main phenomenological features of ionospheric precursors of strong earthquakes, J. Atmos. Sol.-Terr. Phy., 65, 1337-1347, 2003.

Rozhnoi, A., Solovieva, M., Molchanov, O., Akentieva, O., Berthelier, J. J., Parrot, M., Biagi, P. F., and Hayakawa, M.: Statistical correlation of spectral broadening in VLF transmitter signal and low-frequency ionospheric turbulence from observation on DEMETER satellite, Nat. Hazards Earth Syst. Sci., 8, 11051111, doi:10.5194/nhess-8-1105-2008, 2008.

Rishbeth, H.: How the thermospheric circulation affects the ionospheric F2-layer, J. Atmos. Sol.-Terr. Phy., 60(14), 1385-1402, 1998.

Sarkar, S., Gwal, A. K., and Parrot, M.: Ionospheric variations observed by the DEMETER satellite in the mid-latitude region during strong earthquakes, J. Atmos. Sol.-Terr. Phy., 69, 1524-1540, 2007.

Sharma, K., Das, R. M., Dabas, R. S, Pillai, K. G. M., Garg, S. C., and Mishra, A. K.: Ionospheric precursors observed at low latitudes around the time of koyna earthquake, Adv. Space Res., 42, 1238-1245, 2008.

Zaslavski, Y., Parrot, M., and Blanc, E.: Analysis of TEC measurements above active seismic regions, Phys. Earth Planet. Int., 105, 219-228, 1998.

Zhang, X., Shen, X., Liu, J., Ouyang, X., Qian, J., and Zhao, S.: Analysis of ionospheric plasma perturbations before Wenchuan earthquake, Nat. Hazards Earth Syst. Sci., 9, 1259-1266, doi:10.5194/nhess-9-1259-2009, 2009.

Zhu, R., Yang, D. M., Jing, F., Yang, J. Y., and Ouyang, X. Y.: Ionospheric perturbations before Pu'er earthquake observed on DEMETER, Acta Seismol. Sin., 21(1), 77-81, doi:10.1007/s11589-008-0077-8, 2008.

Zou, L., Rishbeth, H., Muller-Wodrag, I. C. F., Aylward, A. D., Millward, G. H., Fuller-Rowell, T. J., Idenden, D. W., and Moffett, R. J.: Annual and semiannual variations in the ionospheric F2-layer, I, Modelling, Ann. Geophys., 18(8), 927-944, 2000. 